\title{
Static Security Analysis of Double Branch Outage Contingency
}

\author{
Yousuf Mohammad Younes \\ Department of Electrical Engineering \\ Collage of Engineering, Mosul University \\ Mosul, Iraq
}

\author{
Abdul Ghani A. A, Phd \\ Department of Electrical Engineering \\ Collage of Engineering, Mosul University \\ Mosul, Iraq
}

\begin{abstract}
This research analyse the static security of the electrical power system according to the security constraints after the transient state of the $\mathrm{N}-2$ Contingency, i.e., two components outage together. Active power performance index $\left(\mathrm{PI}_{\mathrm{P}}\right)$ has had the greatest share of attention because of overloading some branches which led to cascading outages which led to isolating of some loads. Several techniques have been taken to reduce this deterioration and mitigate the transmission system from the consequences of it such as using a HVDC Link instead of a HVAC Link, addition of a line parallel to the line that suffers from overload and small local generation stations to ensure security. The IEEE 14 Bus system was selected as a model for study and representation in MATLAB.
\end{abstract}

\section{Keywords}

Static security analysis, Contingency, Double branch outage, Active power performance index.

\section{INTRODUCTION}

Power system security is as an important aspect in planning, design and operation stages, where the main goal preserving the state of a secure power system exists in assuring the ability to deliver all the connected loads at different conditions even at worst conditions at which the system may suffer from them, as far as possible, without violating any operational constraints which may lead to shed the service to the load/loads by withstanding these disturbances [1,2]. Maintaining power system in secure state is a basic requirement in the operation plus planning and control of a power system because the power systems may being operated under highly stressed operating conditions which refer to harmful contingency $[3,4]$, like: Increasing of demand which may lead to congestion of grid and then a cascading collapse leading to a major blackout[5], or forcing to a single branch outages where some of these single outages are harmful $[6,7]$, and bad operation of protection or control systems or human errors or vandalism or severe weather conditions or natural disasters, missing/ uncertain/lack informations [8].This paper is focused on steady state security at off line, because it is interested in what happened at post contingency to distinguish between the secure state and the insecure state.

\section{THERMAL SECURITY CONSTRAINT}

The thermal security constraint(SC) or security operational limits which refer to normal (secure) operation of the power system is necessary to recognize the operation state of the power system, if normal or not. The strategy of static security assessment dealt with the evaluation of the power system status for various probable contingencies and the results are compared with system constraints for different post contingency scenarios, the system operating state is labeled as secure, if SC is satisfied for a given operating condition under contingencies.

While if the operation limit of SC is violated for any postcontingency scenario, the system operating state is classified as insecure $[9,10]$.

In order to operate the system within an acceptable security domain, the basic security constraints, two algebraic sets of equations are comprise of equality and inequality constraints run power system operation [11,12].

The inequality constraints (I) define a permissible levels limitations within rated values which some system variables must not exceed it . The inequality constraints (I) include bus voltage magnitudes (bus voltage security limits) and thermal limits of transmission lines and transformers (line power flow security limits) [13,14].

In details, the thermal limit of transmission lines represented by line flow security limit:

$\mathrm{P}_{\mathrm{k}-\mathrm{m}} \leq \mathrm{P}_{\mathrm{k}-\mathrm{m}-\text { limit }}$

$P_{\mathrm{k}-\mathrm{m}}:$ represents the active power flow at branch k-m;

$P_{\mathrm{k}-\mathrm{m} \text {-limit }}:$ represents the thermal limit for active power flow at branch k-m.

The violations of thermal limits of branches is the main concern for static security analysis [15].

\section{ACTIVE POWER PERFORMANCE INDEX (PIP)}

The contingency ranking is done in the descending order according to value of $\mathrm{PI}_{\mathrm{P}}$ to discriminate and measure the degree of line over loads and then critical contingencies which having PIP values greater than "1", to give planners, operators a very quickly list of "worst case" contingencies.

Computation of $\mathrm{PI}_{\mathrm{P}}$ it is required to check the active power limits of all branches in the power system against their respective limits for each outage tested. The $\mathrm{PI}_{\mathrm{P}}$ will be less than 1 if active power flow is within permissible thermal limit, and it will be large than 1 if any branch is overloaded [16,17].

$$
\mathrm{PI}_{\mathrm{P}}=\frac{\mathrm{P}_{\mathrm{i}}}{\mathrm{P}_{\mathrm{ij} \max }}
$$

Where,

$P_{i}$ : active power flow in line $i$,

$\mathrm{P}_{\mathrm{i}}^{\max }$ : maximum active power flow (thermal limit) in line $\mathrm{i}$ /the MW capacity of line i. 
Figure (1) show the processes of contingency definition, ranking and selecting contingency

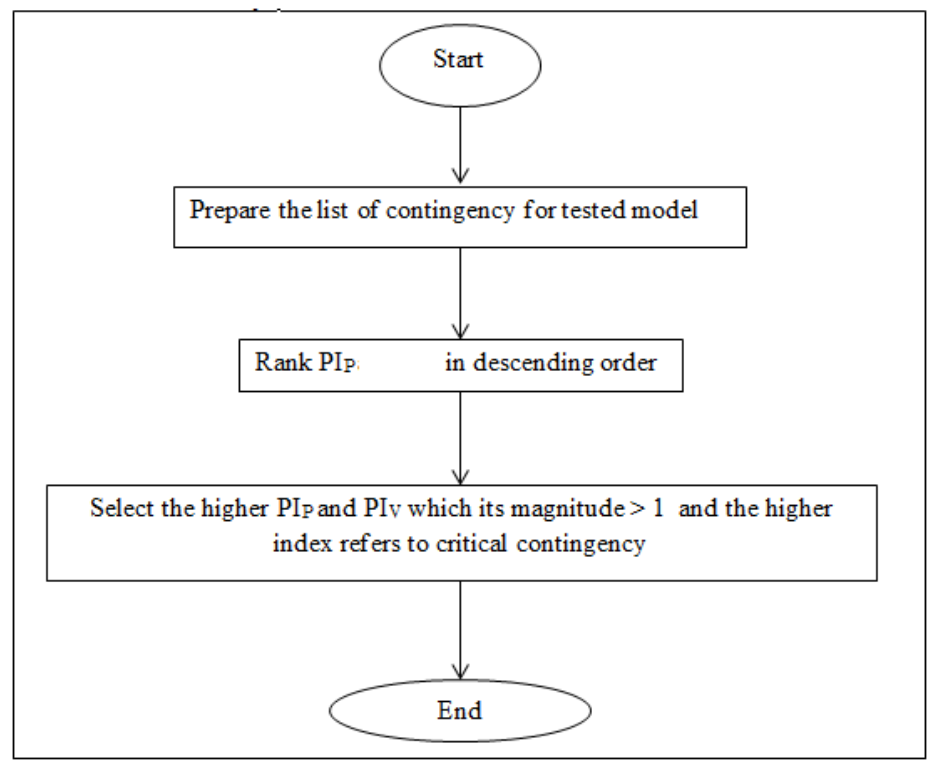

Fig 1 Flow chart for contingency selection

\section{RESULTS OF DOUBLE BRANCH OUTAGE CONTINGENCY}

Is the second axis of the study of the analysis of the static security of the system under test, where this axis deals with the hypothesis of the outage of two branches randomly at same time to identify the worst case double outage contingency and then to propose appropriate treatment, as shown in figure (2) as a sample of double branches outage contingency. The contingency definition process included 190 cases, but the worst cases were only 13 cases which lead to the heavy loading of branches and perhaps the interruption of power supply on some loads, hence, islanding it from the system and lose the security of the system as shown in the following two tables.

Table 1: The worst double branch outage contingency and their consequences according to heavy loaded branches.

\begin{tabular}{|c|c|c|c|c|c|}
\hline Number & $\begin{array}{c}\text { Branch } \\
\text { outage }\end{array}$ & With branch outage & $\begin{array}{c}\text { Heavy loaded } \\
\text { branch }\end{array}$ & $\begin{array}{c}\text { Percentage of heavy } \\
\text { loading\% }\end{array}$ & $\mathrm{V}_{\min }$ \\
\hline 1 & $6-11$ & $7-9$ & $13-14$ & 115.6 & 0.9332 \\
\hline 2 & $6-12$ & $6-13$ & $9-14$ & 163.1 & 0.865 \\
\hline 3 & $6-13$ & $7-9$ & $10-11$ & 104.6 & 0.9417 \\
\hline 4 & $6-13$ & $9-14$ & $6-12 \& 12-13$ & $116.4,135.2$ respectively & 0.8935 \\
\hline 5 & $6-13$ & $12-13$ & $9-14$ & 141.6 & 0.9112 \\
\hline 6 & $7-9$ & $4-9$ & $10-11 \& 13-14$ & $143.9 \& 113.9$ respectively & 0.9179 \\
\hline 7 & $7-9$ & $10-11$ & $13-14$ & 108.7 & Normal \\
\hline 8 & $7-9$ & $13-14$ & $10-11$ & 122 & Normal \\
\hline
\end{tabular}


Table 2: The worst double branch outage contingency and their consequences according to islanding of bus load.

\begin{tabular}{|c|c|c|c|}
\hline Number & Branch outage & With branch outage & Islanding bus load \\
\hline 1 & $6-11$ & $9-10$ & 11 \\
\hline 2 & $6-11$ & $10-11$ & 12 \\
\hline 3 & $6-12$ & $12-13$ & 10 \\
\hline 4 & $9-10$ & $10-11$ & 14 \\
\hline 5 & $9-14$ & $13-14$ & \\
\hline
\end{tabular}

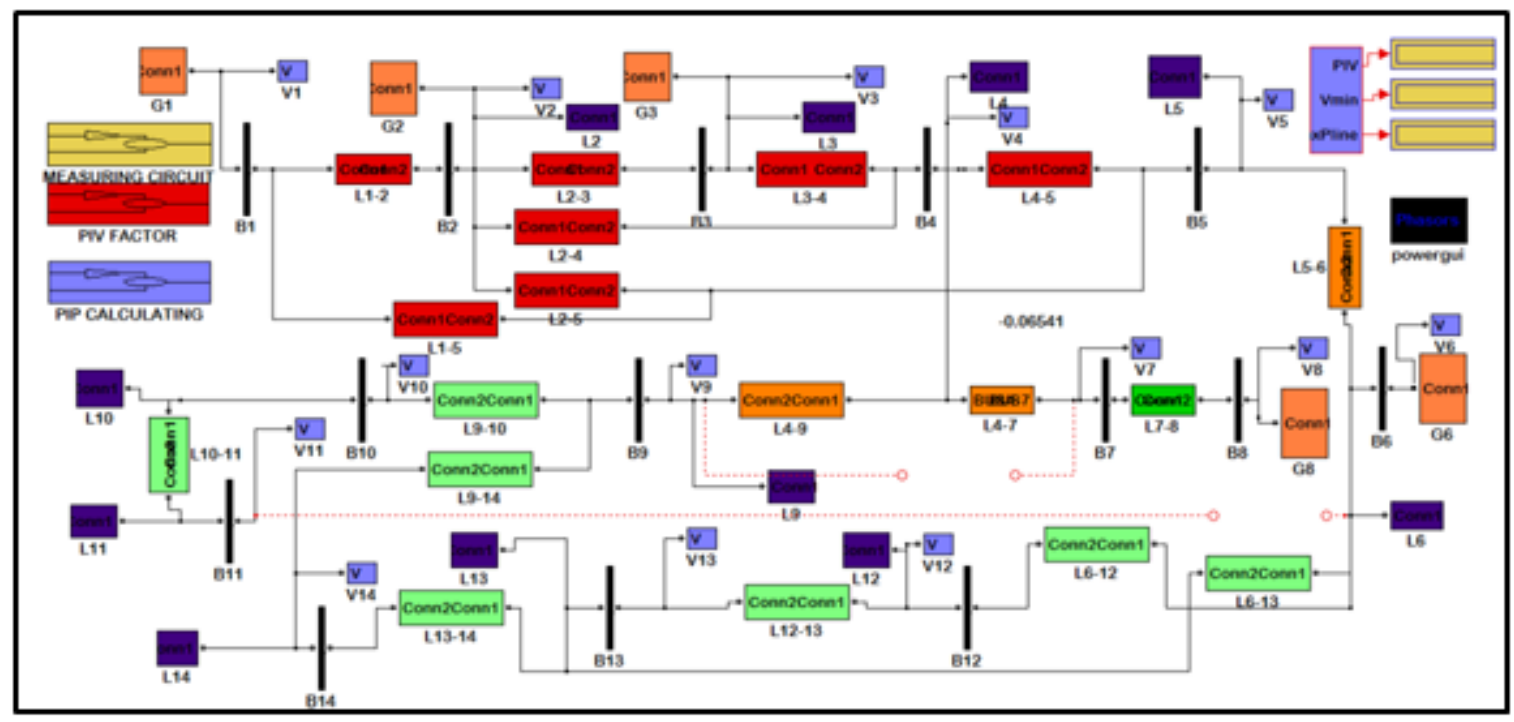

Fig 2: Simulation of outage line 6-11 with line 7-9.

As shown from table (1), the critical lines which suffer from heavy loaded at worst double outage contingency are 6-12, 9$10,9-14,10-11,12-13$ and 13-14. To treat the problem of heavy loaded for critical lines and give the system the ability to withstand the worst possible double branches outage if happened in the future, there are some suggestions to do that ,as below:

\subsection{Adding Series Capacitance To Critical Lines}

The above mentioned critical lines are treated by adding a series capacitor with $40 \%$ of its inductive reactance value, and the improvement of performance of the tested system at worst double contingency, is shown in figure (3). 


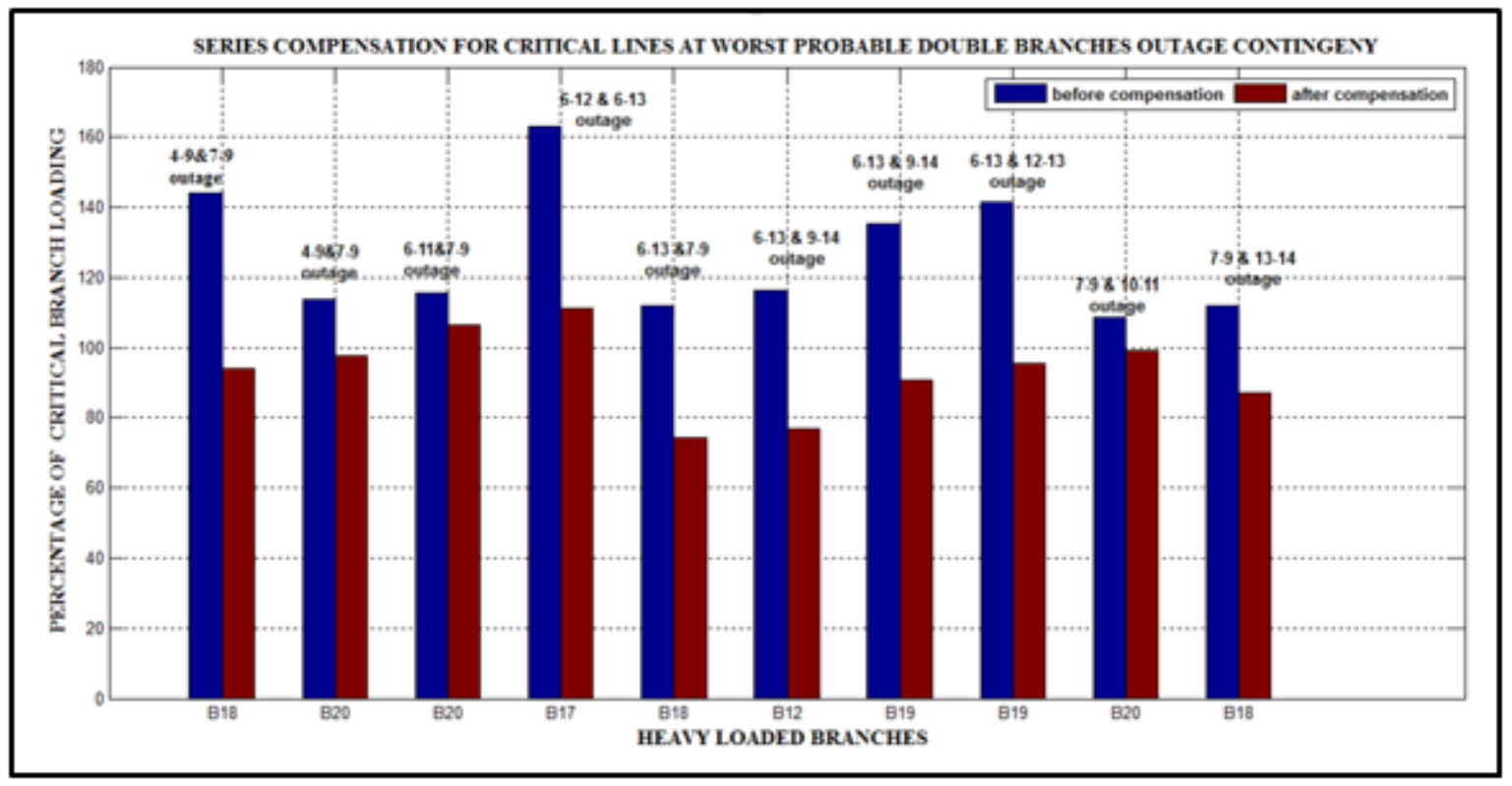

Fig 3: Series compensation for critical lines at worst probable double branches outage contingency.

It is clear from above that line13-14 (B20) and line 9-14 (B17) are still suffer from heavy loading at 6-11 with 7-9 and 6-12 with 6-13 outages respectively.

\subsection{Replacing AC T.L. by HVDC T.L.}

So the second suggestion for each of these two lines is replacing the ac line by dc line to robust the tested system at these worst situations. The results for this improvement is shown in the below figure.

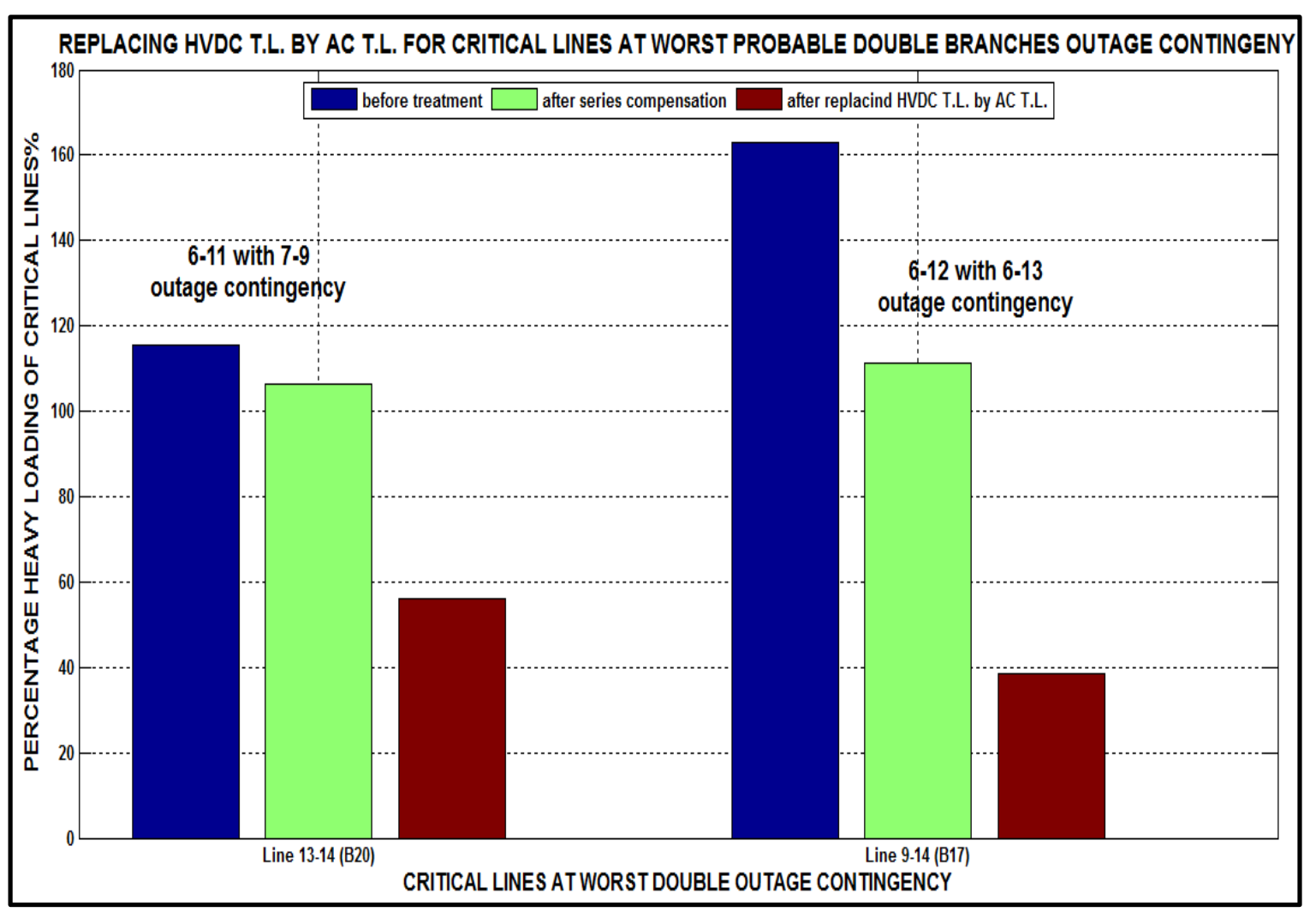

Fig 4: Percentage heavy loading of critical lines when replacing AC Link by HVDC Link at worst probable double branches outage contingency.

It is clear from above figure, the treatment is successful and efficient.
In spite of this progress in treatment the worst cases at double branch outage but danger of another cases which is noticed in table (2) are still unsolved. 
However, there are another solutions to overcome these worst cases and maintain the ability of the system to withstand these worst disturbances, as shown below.

\subsection{Adding a Parallel Line}

As from table (2) there are five cases at which outage of two branch result islanding some loads from the system. There are two branches if outage at this type of contingency have more probability for isolating the bus loads. These branches are B11 (6-11) and B12 (6-12). The solution is adding a parallel line with each of mentioned branch as shown in below figure.

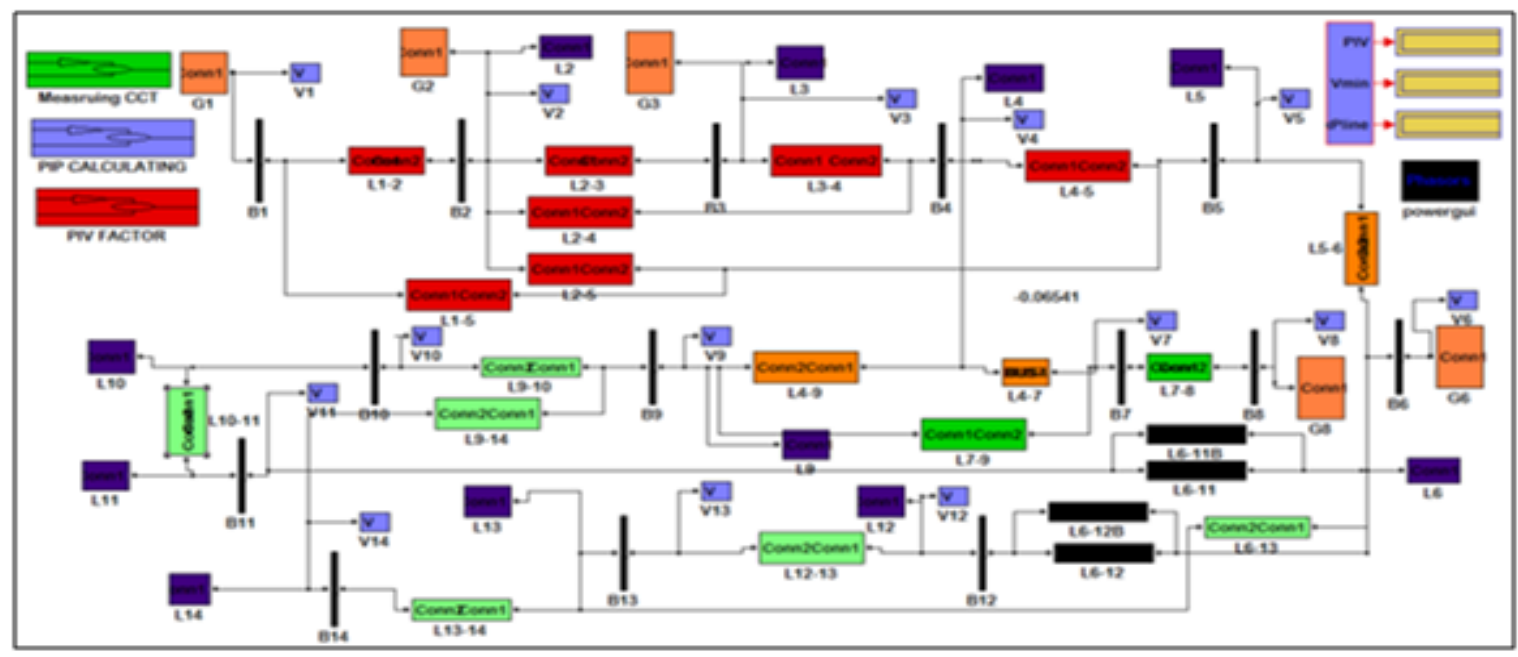

Fig 5: Adding a parallel line to B11 and B12 to prevent isolating some load buses.

Three cases is treated, but there are two unsolved problems, as shown in below table:

Table 3: Unsolved worst cases.

\begin{tabular}{|c|c|c|c|}
\hline Unsolved problem & Branch outage & With branch outage & Islanding bus load \\
\hline 1 & $9-10$ & $10-11$ & 10 \\
\hline 2 & $9-14$ & $13-14$ & 14 \\
\hline
\end{tabular}

The treatment for last unsolved is investigated by connect a local generation station such as gas turbine station at both of load bus 10, load bus 12 and load bus 14, as shown in figure6.

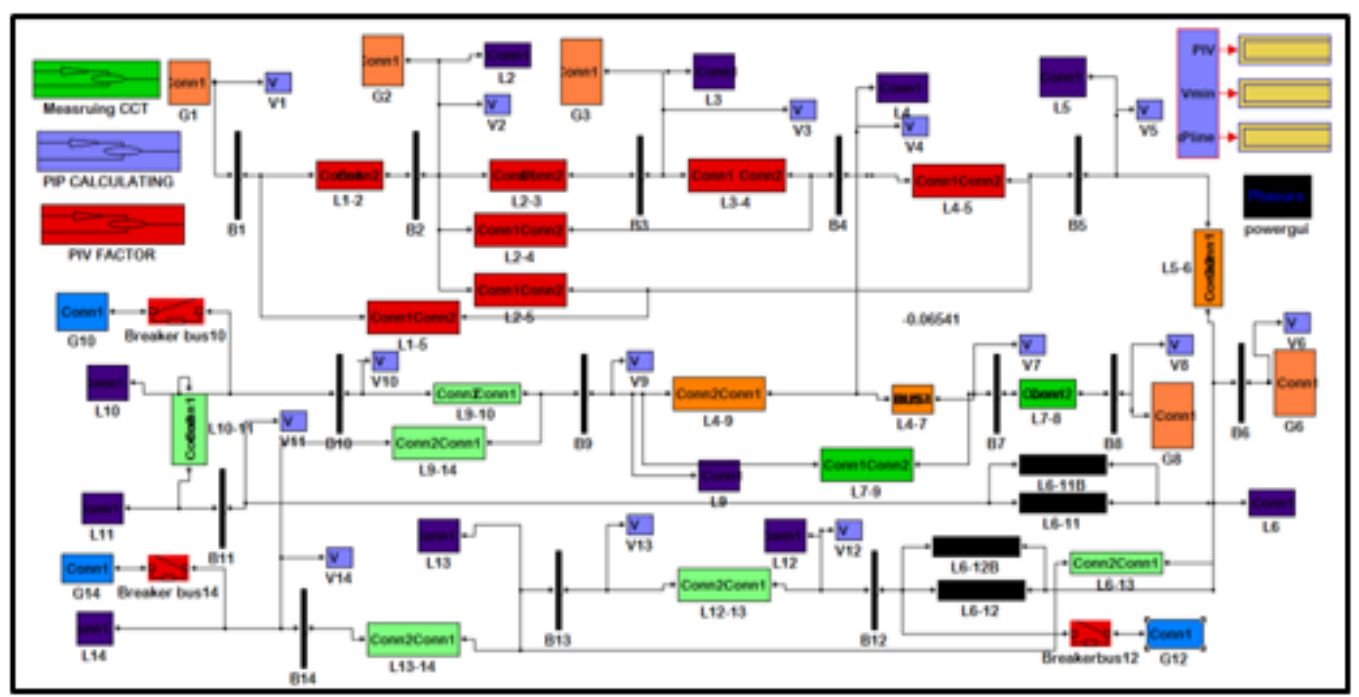

Fig 6: Connect a local generation station at critical load bus(10,12 and14).

\section{CONCLUSION}

The static security analysis of IEEE 14bus was dependent on some performance indices to assess the security. These indices gave a good indication on the security state for different types of contingencies. Contingency analysis is an efficient in probable contingencies definition, selecting the worst cases and evaluating the security state. Maintain the secure operation of the power system at insecure state by identifying 
the most severe contingency and its consequences, which refer to (N-2-1 Security) where the worst cases are chosen according to value of the $\mathrm{PI}_{\mathrm{P}}$ to determine the state of the system, secure or not for outage of double branch. $\mathrm{PI}_{\mathrm{P}}$ has had the greatest share of attention because of the consequences that may being resulted from the outage of two branches, which led to exceeding the permissible limits of the thermal limit through some branches.

Critical lines have been identified, which result in isolating some loads.

Series compensation, additive a parallel line to a weaker line and replacing an AC Link by a DC Link are used to overcome the impact of deterioration resulting from severe contingencies when they occur.

\section{REFERENCES}

[1] Pudi Sekhar, "Assessment and Enhancement of Power System Security using Soft Computing and Data Mining Approaches" Ph.D. Thesis, National Institute of Technology Rourkela, January, 2016.

[2] S. Ravindra, V. C. Veera Reddy and S. Sivanagaraju, "Power System Severity Analysis under Generator Outage Condition", International Journal of Advanced Research in Electrical, Electronics and Instrumentation Engineering, Vol. 4, Issue 1, January 2015.

[3] S. Kalyani, "A Unified Approach for Security Assessment of Power Systems Using Pattern Classifiers", Ph.D. Thesis, Department of Electrical Engineering Indian Institute of Technology Madras, India, October 2010 .

[4] Neal Balu, Bose, Lester Fink and Wollenberg, "On-Line Power System Security Analysis", IEEE, VOL. 80, NO. 2, FEBRUARY 1992.

[5] Christian Andersson, "Power System Security Assessment Application of Learning Algorithms", Licentiate Thesis, Department of Industrial Electrical Engineering and Automation, Lund University, Sweden, 2005.

[6] Bruce F. Wollenberg, "Power System Operation and Control", University of Minnesota, 2001.

[7] Toshi Mandloi and Anil K Jain, "A Study of Power System Security and Contingency Analysis", International Journal of Scientific Research Engineering \& Technology (IJSRET), Volume 3, Issue 4, July 2014.

[8] B.Likhitha, J.Srinivasa Rao and J.Amarnath, "Sensitivity Approach for the Effective location of TCSC in a Deregulated Electricity Market", IOSR Journal of Engineering (IOSRJEN), Volume 2, Issue 6, June 2012.
The conclusions are summarized, as following:

1- For double outage contingency, HVDC link is more efficient than series compensation in some worst cases.

2- For double outage contingency, connect a parallel line to a critical line to prevent the disconnecting of load/loads.

3- For double outage contingency, in some worst cases the above techniques are incapable to prevent islanding a load/some loads, hence, according to this failure, the suitable location of a local generation station/stations is/are determined.

[9] Dr.Hossam Talaat, "Fundamentals of Power System Operation", Power Horizon International Resources, Inc, 28July-1 August, 2001.

[10] James Brooks, "Security Assessment in Future Power Systems", Ph.D. Thesis, University of Bath, May 2013.

[11] Mohamed E. El-Hawary, "Introduction to Electrical Power Systems", the Institute of Electrical and Electronics Engineers, Inc. 2008.

[12] P.R. Sharma, Rajesh Kr.Ahuja, Shakti Vashisth and Vaibhav Hudda, "Computation of Sensitive Node for IEEE- 14 Bus system Subjected to Load Variation", International Journal of Innovative Research in Electrical, Electronics, Instrumentation and Control Engineering, Vol. 2, Issue 6, June 2014.

[13] Mohammed Abdulla Abdulsada and Dr. Firas M. Tuaimah, "Power System Static Security Assessment for Iraqi Super High Voltage Grid", International Journal of Applied Engineering Research, Volume 12, Number 19, 2017.

[14] Prabha Kundur, "Power System Security in the New Industry Environment: Challenges and Solutions", IEEE Toronto Centennial Forum on Reliable Power Grids in Canada, October 3, 2003.

[15] Niraj H. Patel1 Visha, Thakkar Hemant and N. Raval, "Contingency Analysis in Power System and Remedial Actions" , IJSRD - International Journal for Scientific Research \& Development, Vol. 3, Issue 03, 2015.

[16] X.-F. Wang et al., "Modern Power Systems Analysis: Chapter 2 ",2008.

[17] Timothy Allen Ernster, "Power System Vulnerability Analysis A Centrality Based Approach Utilizing Limited Information" , M.Sc.Thesis, Washington State University, School of Electrical Engineering and Computer Science, August, 2012. 